\title{
The Anatomy of Working Memory and Its Utility in Criminal Investigations
}

\author{
J. Adam Park \\ Criminal Investigator, Beaumont, TX, USA \\ Email: hyperion1975@aol.com
}

How to cite this paper: Park, J.A. (2017) The Anatomy of Working Memory and Its Utility in Criminal Investigations. Open Journal of Social Sciences, 5, 258-271. https://doi.org/10.4236/jss.2017.58021

Received: July 3, 2017

Accepted: August 27, 2017

Published: August 30, 2017

Copyright $\odot 2017$ by author and Scientific Research Publishing Inc. This work is licensed under the Creative Commons Attribution International License (CC BY 4.0).

http://creativecommons.org/licenses/by/4.0/

\section{(c) (i) Open Access}

\begin{abstract}
Interest into the area of working memory has increased in recent years. However, there is a lack of empirical exploration regarding how memory contributes directly to forensic investigations. It is suggested a more complete analysis of the nuances involved with working memory is needed in order to bridge the gap between past human behavior and criminogenic outcomes. Practitioners of cognitive, applied, and police psychology have generally asserted that memory is malleable, meaning retrieval outcomes relative to the brain are both delicate and prone to inaccuracies. Yet, the concept of memory has proven to be a staple of the criminal justice system. It is memory that oftentimes serves as the impetus for the advancement of a valid defense to prosecution. Conversely, the accurate, corroborated retrieval of past events can lead to the successful imprisonment of a violent offender. This paper examines the neural bases of memory, and discusses how forensic professionals can enhance the efficacy of retrieval within interview contexts. False and repressed memories will be discussed due to their relevance in criminal investigations. Age considerations and clinical pathology affecting memory will be appraised, as will a section detailing procedural safeguards for practitioners when interviewing involves a memory component.
\end{abstract}

\section{Keywords}

Working Memory, Criminology, Forensics, Psychology

\section{Introduction}

Memory has many applications in criminology. The empirical investigation of memory is more than a century old, dating back to Ebbinghaus's (1885) work on the forgetting curve and spacing effect (Roediger III \& Gallo, 2002) [1]. From a practical perspective, it is the criminal investigator whom is responsible for ex- 
ploiting the utility of memory. It is a journey that both investigator and witness/victim must embark on in order to bring past events to light. This can serve as a cornerstone of placing elements together for a solid homicide case, or the ability to refute allegations of sexual assault in false reporting. It is integral for those involved in criminogenic research, as well as the judicial process, to understand the neural substrates of working memory and its comparative importance to successful outcomes in criminal investigations. As a note, successful outcomes can be defined by advancing empirical knowledge of the subject of memory, acquittal or conviction-as it is the accurate, truthful reporting of events we are chiefly concerned with. As an example, the ability to accurately recover and exploit past events has inherent value not only to criminal investigators, but also serves to complete an explanatory, "functional circle" for attorneys and judges, each of which serve varying purposes in a criminal case. This paper is to serve as a guideline for those involved in criminal investigations and preparation for court in cases involving recall. Extending on this idea, this discussion does not suggest that every police officer should be a psychologist or physiologist; nor should every psychologist or physiologist assume they are an expert in forensic (court-related) interviews or criminal investigations.

It is important to provide an operational definition of forensic interview and place the term into context. In this paper, the term forensic interview is herein described as the process of interviewing a subject (regardless of age) in order to evaluate criteria subject to general criminological outcomes. While the topic of memory relating to child sexual offenses will be described later in the paper, the forensic interview, for our purposes, is not to be an expression isolated to that phenomenon. To this aim, it is suggested the concepts relating to working memory in criminal investigations are subordinate to both cognitive and applied psychological principles.

\section{The Neuropsychology of Memory}

The manner in which humans recall sensory information is remarkable as it is fluid. This paper highlights working memory typologies which contribute to our current understanding of recall specific to forensic applications. There are two recognized frameworks involved in recall: 1) Short-term memory (STM) and; 2) Long-term memory (LTM); both of which have utility in criminal investigations. In neuropsychology parlance we may infer that short-term memory and working memory share organic commonalities; however, working memory is a more complex construct than that of short-term memory (Cowan, 1995) [2]. For example, activation of the dorsolateral prefrontal and posterior parietal regions of both hemispheres, Broca's area, left premotor and supplementary motor cortices have been previously observed using positron emission tomography (Loeb \& Poggio, 2002) [3]. And while advances in cognitive psychology have contributed to a greater understanding of human memory, the field continues to lack a general, accepting theory of executive functions as they relate to cognition (Miyake 
et al., 2000) [4].

In cognitive psychology, we may refer to working memory as a limited capacity system which facilitates the temporary storage and abstract manipulations which are vital for such complex tasks as comprehension, learning and reasoning (Miller et al., 1960 [5]; Baddeley \& Hitch, 1974; [6]). Another, more contemporary illustration of working memory refers to the cognitive ability to actively maintain and control information that is behaviorally relevant (Tsutsui, Oyama, Nakamura, \& Iijima, 2016) [7]. Now I will proffer a few definitions of memory and their relative importance to everyday life, and criminology in general. In criminological contexts involving memory we should be principally concerned with episodic, long-term memory, although short-term memory has applications which will be discussed later. Long-term memory falls beneath the umbrella of declarative memory. Examples of declarative memory include knowing that blue is a color, baseball is a sport, or that Alaska is a state. The left prefrontal cortex is preferentially activated during semantic memory tasks (Loeb \& Poggio, 2002) [3]. It is only recently that researchers have been able to better understand the neurobiology of semantic memory, which contributes to further analyses of its operational definition.

The process of cognitive encoding is engaged when an individual first experiences the event and initiates the storage of information symbolizing the event into episodic memory (Tulving, et al., 1994) [8]. However, there are also applications for the temporary storage and manipulation of information. The theoretical framework of episodic memory is structurally oriented to the past and is the only memory system which allows us to consciously re-experience past events (Tulving, 2002) [9]; it can be studied as either a verbalor enacted event, with separate phases corresponding to encoding and retrieval (Badinlou, KormiNouri, Nasab, \& Knopf, 2017) [10]. The right prefrontal cortex is preferentially activated during episodic retrieval (Loeb \& Poggio, 2002) [3]. Whether an examinee is answering questions to a credibility assessment test, or a subject is attempting to recall the physical features of a perpetrator in a hypnotic interview, they are employing cognitive mechanisms intrinsic to episodic memory. While it is estimated there are multiple perceptual processing streams, the inferior parietal lobe and large portion of the temporal lobe are involved in object recognition, social cognition, and language (Binder \& Desai, 2011) [11]. Procedural memory, as the name implies, denotes the ability to recall how to do certain things. Knowing how to break down an M-16 rifle and then re-assemble it would be a procedural memory task. The brain regions of the basal ganglia and cerebellum are believed to be involved in procedural processes (Mochizuki-Kawai, 2008) [12].

There is substantial evidence which supports a tripartite theory of working memory. Principal to the discussion of models which explain theories of recall is the three-component model (Baddeley \& Hitch, 1974) [6]. This typology suggests an attentional controller, the central executive, is supported by two subsid- 
iary systems, the phonological loop that is adept at holding speech-based information, and the visuospatial sketchpad, which performs a similar function for visual information (Baddeley, 2000) [13]. The two subsidiary systems are often referred to as "slave systems"; referring to their subordinate nature to the central executive. The episodic buffer, a recently added facet of the working memory model, acts as an integrator of information between working memory systems and long-term memory (Baddeley, 2000) [13].

Central executive functions might be described as "higher-ordered" tasks such as the ability to develop a theory (reasoning) or balance a check book (problem solving). Scientific explanations of executive functioning have been described as shifting between tasks or mental sets; updating and monitoring of working memory representations and; inhibition of dominant or prepotent responses (Miyake, et al., 2000) [4]. Cognitive science practitioners have designated the frontal lobe area as responsible for primary central executive functions. Through years of investigation researchers have been able to assess a substantial amount of disorders of executive control to be correlated with frontal lobe damage (Shallice, 1982; 1988) [14]. This has important implications for not only identifying maladaptive behavior, but illustrating the efficacy of findings on the responsible region of executive function, as individuals with frontal lobe damage are oftentimes unable to perform routine, conventional tasks. Traditional neuroanatomical explanations isolate executive functions to the frontal lobes by using psychometrics such as the Wisconsin CardSorting Test (WCST), the Tower of Hanoi $(\mathrm{TOH})$ task and its variant, the Tower of London; each of which specifically tasks the frontal lobes (Miyake). However, recent studies theorize other parts of the brain may play some augmented role with higher-ordered processes (Baddeley, 1996) [15]. So it is the identification of deficits in human behavior which have led enhancements in cognitive science.

The phonological loop represents one sub-system within the context of central executive functioning. An underlying theme of the phonological loop is that acquisition and interpretation of auditory stimuli is a necessary function of life (Burgess \& Hitch, 1999) [16]. Extending on this idea, it is an obvious assumption that verbal accounts of the victim and/or witness are important concepts in criminal investigations involving eyewitness accounts. Paulesu, Frith, and Frackowiak (1993) [17] were able to localize two major neurological sections of the phonological loop using functional brain imaging. The articulatory speech output component was located with Broca's area of the brain; whereas the phonological store was identified with the supramarginal gyrus (Burgess \& Hitch, 1999) [16]. This research is correlated with other neuropsychological findings suggesting Broca's and Werncike's areas linked to the comprehension of speech (e.g., Blumstein, 1995) [18]. Some studies have regionalized syntactic specialization (i.e. word processing) to Broca's area (Embick, Marantz, Miyashita, O’Neil, \& Sakai, 2000) [19]. The neural circuitry associated with the phonological loop is physically located in the left hemisphere, covering some inferior parietal areas 
and more anterior frontal areas; including Broca's area, premotor cortex, and sensory motor association cortex (Henson, Burgess, \& Frith, 2000; [20] Smith \& Jonides, 1997; [21] Smith, Jonides, \& Koeppe, 1996) [22].

The visuospatial sketchpad represents the other formal sub-system of working memory and is thought to be involved in creating and maintaining visuospatial images (Van der Linden, Bredart \& Berteen, 1994) [23]. This component is generally localized in the right hemisphere of the brain and is associated with activations of occipital and inferior frontal areas (Smith \& Jonides, 1997) [21]. In this process, the healthy subject is able to temporarily store and manipulate both visual and spatial information and form them into appropriate context (Baddeley, 2004) [24]. From an investigative perspective, this may perhaps be the most vital component to the outcome of a case. In order to appreciate the true utility the visuospatial sketchpad to memory we must conceptualize an early intervention with witnesses and victims, as studies reveal visual information load imposes limits to visual short-term memory (Alvarez \& Cavanagh, 2004) [25]. It should also be stated that the fractionation of amygdala nuclei (amygdala complex) have implications for memory. Particularly relevant for incidences of violent crime, the amygdala plays a crucial role in explaining memory in emotional contexts. Localized in the area of the amygdala complex (AC), the basolateral (BL) appears to be the nucleus primarily responsible for memory storage (Roozendaal \& McGaugh, 1996; [26] 1997; [27] Killcross, et al. 1997) [28]. Research supports the position that the AC is selectively involved with long-term memory involving emotional-arousing events. As Cahill and McGaugh (1998) [29] note:

An impressively broad array of experimental evidence either directly supports, or is consistent with the hypothesis that stress-hormone systems and the AC are key components of an endogenous memory modulating system. Generally inactive in unemotional learning situations, this system is activated during and after an emotionally arousing event and appears to regulate declarative-memory storage processes in other brain regions (p. 298).

\section{False Memories and False Confessions}

Memories can be physiologically cemented and then successfully retrieved to form valid bases of past events. There are success stories relative to recovering memories which have led to convictions for historical violence abuse (e.g., Loftus, 1993) [30]. In sharp contrast, there must be a discussion on the reality of false memories which may lead to inaccuracies, or in extreme cases, false statements leading to unjustified confessions of criminal activity. Chief Justice William Brennan was noted as saying that a confession essentially makes all other elements of a criminal case superfluous (Colorado v. Connelly, 1986) [31]. This is an opportune time to briefly discuss the fabrication of events which may lead to inaccurate outcomes. If one could explain "an honest lie", it would more than likely involve the scientific examination of confabulation; based in part on false memories. As seen in Brown, et al., (2013), [32] "Confabulation is not a function 
of the disturbed but an action that is part of the human condition. It is not uncommon to create and hold false memories, or even participate in the act of self-deception. Confabulation is simply an act of filling in the holes, creating a semblance of coherency" (p. 1). Honts, Kassin \& Craig (2013) [33] assessed a layperson's ability to recognize false confessions in juveniles and found poor judgment accuracy (52.8\%) across two experiments; suggesting even the seasoned interrogator should exercise care when evaluating confessions. Earlier I discussed the theoretical construct of episodic memory and its importance to criminological contexts. Memories can be corroded or manipulated in definitive ways. While not rising to the level of false memories, episodic memories have been experimentally created in laboratory experiments (Tulving, 1994), [8] illustrating the potency of suggestion. The topics of false memories and subsequent confessions have received much attention in judicial circles. It is, of course, vital that the journey from encoding of stimuli to recollection be accurate and of course to have actually occurred. Studies also show that stress can produce a murky picture for eyewitness recall (Slovenko, 1999) [34].

There is a substantial body of research examining the process whereby our memories fail due to the disruption of earlier events (proactive interference) or things we experience later (retroactive interference) (Loftus \& Pickrell, 1995) [35]. Serious and violent crime can have profound implications for the victim, as well as those who are witness to the event. And while the encoding of pertinent stimuli to the crime would seem common, it is viable to expect mixed themes and inaccuracies with respect to reporting. For example, field case studies have documented that subjects are much more likely to inaccurately report the details of a crime $(30 \%-40 \%)$ when they receive misinformation, as opposed to those subjects who did not receive any additional information (Loftus \& Pickrell, 1995) [35]. The research here was intentional yet served an important purpose: the human mind is malleable and thus care should be employed when conducting inquiry of recall.

\subsection{Age Considerations of Recall}

The age of an individual may influence their ability to remember and accurately recall past events. Given the probability that children may be easily influenced, coupled with the theory that they may acquiesce to social desirability in reporting, it is of interest to examine the psychodynamics involved in this population. Investigations involving a child's recall of events surrounding alleged criminal episodes must obviously be taken seriously, and addressed with informed decisions. Research has shown that age-related differences exist in a child's ability to recall episodic events (Farrar \& Goodman, 1992) [36]. While research has shown that children 1 year of age are able to repeat sounds as a measure of memory, the first episodic or autobiographical memory for a child begins on average around the age of $31 / 2$ (Schneider \& Pressley, 2013) [37]. Additionally, the developing brain is capable of retaining sensory information in dramatic fashion, but only 
for a brief time during childhood (Gathercole, 2009) [38]. Empirically, we know that children younger than 7 generally defer to the visuospatial sketchpad in order to recall physical form stimuli (Gathercole, Pickering, Ambridge, \& Wearing, 2004) [39].

It is believed that young children ( $1-2$ years) are incapable of independently forming episodic memories. Instead, children often listen to their parent's accounts of things that have happened to them, and therefore develop a subjective understanding of what needs to be included in a memory (Schneider \& Pressley, 2013) [37]. In using the aforementioned example we could imply that children "learn" how to remember in order to recount events to others. Our ability to retain sensory information dramatically increases during childhood (Gathercole, 1999) [40]. Laboratory studies which examine a child's ability to discriminate between faces seen and not previously seen suggest memory is enhanced between the ages of 5 - 10 (Davies, 1993) [41]. However, for unknown reasons, performance on similar tasks appears to decline dramatically after the age of 10 (e.g., Carey, Diamond, \& Woods, 1980 [42]; Flin, 1980) [43].

There are numerous applications to understanding memory development in children such as a peripheral witness to a crime, or being a victim of sexual abuse. Some studies which examine fragments of memories from children reporting childhood sexual abuse note inaccuracies or distortions due to difficulties of the memories location in a temporal or special context (Kopelman, 2010) [44]. The most popular methodology for assessing the credibility of a child's recollection of events relative to sexual offenses is Statement Validity Assessment (Vrij, 2000) [45]. A checklist has been devised in order to guide those who utilize Statement Validity Assessment. These items are common but not all inclusive: "(a) appropriateness of language and knowledge (mental capability of the child); (b) appropriateness of affect shown by the interviewee; (c) interviewee's susceptibility to suggestion; (d) evidence of suggestive, leading, or coercive questioning; (e) overall adequacy of the interview and; (f) motives to report" (Vrij, 2005, p. 7) [46]. Novel processing of executive function in children is a continually evolving physiological process within human development. While the majority of physical features in children remain undeveloped until adulthood, the total brain volume of a child will have reached $90 \%$ of an adult brain by age 5 (Lenroot \& Giedd, 2006) [47].

Repressed memory is an item worthy of brief discussion here due in large part to its general legal applicability in child sexual abuse (CSA) cases. What is a repressed memory? To use a contextual comparison, many therapists believe that individuals who claim childhood sexual abuse are able to "repress" memories of the reported event at a sub-conscious level, which ultimately serves as a coping mechanism to forget memories traumatic in nature (Clancy, Schacter, McNally, \& Pitman, 2000) [48]. Elizabeth Loftus has extensively examined working memory and the frequency in which adults report repressed childhood memories of sexual abuse. In her work, Loftus (1993) [49] describes the strategy of determining the precedence of repressed memories in childhood sexual abuse as essen- 
tially "asking people about a memory for forgetting a memory". Beliefs about the commonness of repressed memories have raised the curiosity of mental health clinicians, as well as legal scholars who have used beliefs to change legislation about repressed memories.

Studies examining the acquisition of mnemonic (e.g., effortful, capacity-consuming processes) strategies suggest discernable differences between that of children and adults. As Gaultney, Kipp and Kirk (2005) [50] note, "In children, maturation and increasing knowledge are confounded, making it difficult to disentangle the effects of these possible sources of utilization deficiencies. Adults, however, are typically assumed to be mature, effective strategists, and therefore examining their performance may eliminate some of the potential confounding" (p. 206). On the other side of the coin there is ample evidence to suggest that aging has a defined impact on memory (Kausler, 1991; [51] Salthouse, 1991), [52] although the theory itself is not fully understood. Episodic memory has been found to markedly decrease as one ages, which is likely due to neuronal changes in the brain (Nyberg, Backman, Erngrund, Olofsson, \& Nilsson, 1996) [53]. Multiple factors are associated with memory decline in the aging population. For example, the depletion of certain neurotransmitters may influence both executive functioning and the medial temporal lobe memory system (Buckner, 2004) [54].

\subsection{Psychopathological Considerations of Recall}

Individuals who suffer from neurological impairments are at a distinct disadvantage when being questioned by police (Brown, et al., 2013) [32]. An exhaustive discussion of pathological determinants affecting working memory is not appropriate for this paper. However, I will provide a brief overview of a few ideas to be considered regarding general effects on memory and testimony. It is of interest for investigators to pursue valid confessions. But to what extent does pathology contribute to errors in recall when they are part of that confession? It is estimated that $12 \%$ of European prisoners have falsely confessed (Gudjonsson, 2003), [55] while research examining 261 Icelandic students with Attention Deficit Hyperactivity Disorder (ADHD) reportedly had falsely confessed (Gudjonsson, Sigurdsson, Sigfusdottir, \& Young (2012) [56]. As seen throughout the paper, there are various factors which can affect recall for eyewitness accounts. Mental illness is one of them. In previous times it was thought that the negative substrates of semantic and episodic memory were both affected by damage to the hippocampal system; however, cognitive development and semantic systems are now believed to be unaffected by hippocampal damage, leaving, unfortunately, the altered area to episodic memory Vargha-Khadem et al., 1997) [57]. Without much expansion, it is important to briefly mention the dynamics of drugs in our discussion of memory.

Fetal Alcohol Spectrum Disorder can largely affect executive function and higher-ordered processes (Brown, et al., 2013) [32]. Korsakoffs Syndrome is 
marked by memory impairment derived from temporal confusion (Kessels et al., 2008; [58] Van Oort \& Kessels, 2009) [59] and is a neuropsychiatric condition characterized by amnesia in the absence of dementia (Krabbendam, et al., 2000) [60]. Traumatic Brain Injury is another anatomical feature which can affect memory. Amnesic and confabulatory symptoms have been seen in patients with damage to the prefrontal cortex (Barba, Boissé, Bartolomeo, \& Bachoud-Lévi, 1997) [61]. Schizophrenia has a wide-array of mental health implications and is often marked by and individual's delusional beliefs, often appearing to be bizarre in nature (Kopelman, 2010) [45]. Psychopharmacology plays an integral role for many suffering from mental illness. Conversely, there are impacts from a drug's use by those that abuse them for non-medical pursuits. In either context, the effect of drugs on memory is largely dependent on whether the drug's principal action targets the receptor or effector systems or on the central nervous system (Singh \& Dhawan, 1992) [62].

\section{Procedural Safeguards in the Forensic Interview}

General criminological research supports the notion that psychological vulnerability may cause ethical and procedural issues for those conducting the forensic interview (Herrington and Roberts, 2012) [63]. From the onset, an interviewer has the ethical obligation to make a holistic evaluation of the subject to be interviewed in order to avoid altering memory processes. When attempting to retrieve information from a witness or victim, it is plausible to assume one may execute the craft with bias and preconceived ideas of what actually occurred. In the spirit of maintaining impartiality it is important to develop rapport. The classic cognitive interviewing style incorporates rapport building from the onset as a measure to notify the witness, victim, or suspect that the interviewer is interested in what they have to say. While closure is oftentimes the ultimate goal of a case, the nuances of memory and valid strategies of forensic interviewing should be observed. Leading a subject to answering is perhaps the most commonly violated principle of interviewing. Anecdotally, it is plausible to assume this is a major contributor to false confessions and inadmissibility of statements at trial.

Suggesting an outcome without corroboration is another fatal flaw common to interviewing. As we have seen, memory is a malleable, fragile concept and every effort should be used in order to preserve "spatial evidence". Implanting uncorroborated facts through leading questions can have devastating effects to the interview process. It is important to maintain an impartial line of questioning; particularly when dealing with children or vulnerable populations. O'Mahony et al. (2012) [64] provides that false confessions of vulnerable populations (i.e. children under 18 years; mental impairment) share key features-(a) suggestibility; (b) acquiescence and; (c) compliance. Acquiescence is simply a fancy word to convey that someone agrees with an idea. For example, an interviewee may concur that he or she intended to commit a crime based solely on the perceived 
power of the interviewer and environment in which it occurs. Extending on this idea, the interviewer can increase the odds of recall by ensuring the similarity of linguistics, as studies show that episodic and semantic long-term memory can be better recalled when the same language is used for both encoding and retrieval.

There are two viewpoints regarding expertise of outcomes relative to psychological principles. The first suggests that only licensed mental health professionals should proffer empirical, expert opinions regarding criminology, psychology, and it's various applications; to include memory. One plausible and credible idea is that clinicians have advanced degrees in psychology and have, at one point or another, studied the subject matter of memory. The latter posits those involved in the day-to-day application of forensic interviewing are competent due to their extensive training in interview, interrogation, and other advanced knowledge of associated psychological principles. In either case, it is vital the interviewer have requisite knowledge of strategies which commonly produce positive outcomes. A positive outcome may be defined as the ability to retrieve valid information from a subject which was previously non-existent, or an aptitude to disprove allegations through forensic discourse and corroboration. An interviewer or expert witness must have received education through advanced training and experience interviewing diverse populations. While there is obvious, inherent value to mental health applications and criminology, the actuarial element must be firmly seated in applied experience of our topic. The assessment of an offender's mental state at the time of offense, diagnostic characteristics of psychopathology, and explanations of repressed memories include examples where forensic services should be isolated to a licensed mental health professional; primarily due to licensing laws in each state. Whether one is a licensed psychologist or seasoned officer, the common denominator relative to the efficacy of memory in criminal contexts is the individual who is adept at conducting the forensic interview (see Kumho Tire Co., Ltd. v. Carmichael et al., 1999 [65] on technical or other specialized knowledge).As seen earlier in the paper, a forensic interview is herein described as the process of interviewing a subject (regardless of age) in order to evaluate criteria subject to general criminological outcomes.

\section{Conclusion}

There are various psychophysiological elements to consider when examining the neural bases of memory as they relate to investigative outcomes. We have seen the various contributors to short and long-term memory, as well as the fallibility of memory and the steps that individuals can take to minimize outliers which can have a negative impact on forensic interviewing. However, one consistent theme is that memory plays an important role within criminogenic terms. Additionally, having an advanced understanding of the anatomy of memory has practical value to criminology researchers, investigators, attorneys and judges alike. An advanced understanding in this area will lead to others' expansion on the subject; therefore, conferring a benefit to criminology and science as a whole. 


\section{References}

[1] Roediger, H.L., Gallo, D.A., Eisen, M.L., Quas, J.A. and Goodman, G.S. (2001) Memory and Suggestibility in the Forensic Interview. Routledge, New York.

[2] Engle, R.W., Tuholski, S.W., Laughlin, J.E. and Conway, A.R. (1999) Working Memory, Short-Term Memory, and General Fluid Intelligence: A Latent-Variable Approach. Journal of Experimental Psychology: General, 128, 309.

[3] Loeb, C. and Poggio, G.F. (2002) Conscious Experience. In: Neural Substrates of Memory, Affective Functions, and Conscious Experience, Springer, Berlin, Heidelberg, 51-81. https://doi.org/10.1007/978-3-642-59432-8_4

[4] Miyake, A., Friedman, N.P., Emerson, M.J., Witzki, A.H., Howerter, A. and Wager, T.D. (2000) The Unity and Diversity of Executive Functions and Their Contributions to Complex "Frontal Lobe" Tasks: A Latent Variable Analysis. Cognitive Psychology, 41, 49-100. https://doi.org/10.1006/cogp.1999.0734

[5] Miller, E.G. and Pribram, K.H. (1960) Plans and the Structure of Behavior. Holt, New York. https://doi.org/10.1037/10039-000

[6] Baddeley, A.D. and Hitch, G. (1974) Working Memory. In: Bower, G.A., Ed., The Psychology of Learning and Motivation, Academic Press, 48-79.

[7] Tsutsui, K.-I., Oyama, K., Nakamura, S. and Iijima, T. (2016) Comparative Overview of Visuospatial Working Memory in Monkeys and Rats. Frontiers in Systems Neuroscience, 10, 99. https://doi.org/10.3389/fnsys.2016.00099

[8] Tulving, E., Kapur, S., Craik, F.I., Moscovitch, M. and Houle, S. (1994) Hemispheric Encoding/Retrieval Asymmetry in Episodic Memory: Positron Emission Tomography Findings. Proceedings of the National Academy of Sciences, 91, 2016-2020. https://doi.org/10.1073/pnas.91.6.2016

[9] Tulving, E. (2002) Episodic Memory: From Mind to Brain. Annual Review of Psychology, 53, 1-25. https://doi.org/10.1146/annurev.psych.53.100901.135114

[10] Badinlou, F., Kormi-Nouri, R., Mousavi Nasab, S.H. and Knopf, M. (2017) Developmental Differences in Episodic Memory across School Ages: Evidence from Enacted Events Performed by Self and Others. Memory, 25, 84-94. https://doi.org/10.1080/09658211.2015.1126607

[11] Binder, J.R. and Desai, R.H. (2011) The Neurobiology of Semantic Memory. Trends in Cognitive Sciences, 15, 527-536.

[12] Mochizuki-Kawai, H. (2008) Neural Basis of Procedural Memory. Brain and Nerve, 60, 825-832.

[13] Baddeley, A. (2000) The Episodic Buffer: A New Component of Working Memory? Trends in Cognitive Sciences, 4, 417-423.

[14] Shallice, T. (1988). Specialisation within the Semantic System. Cognitive Neuropsychology, 5, 133-142.

[15] Baddeley, A. (1996) Exploring the Central Executive. The Quarterly Journal of EXperimental Psychology: Section A, 49, 5-28. https://doi.org/10.1080/713755608

[16] Burgess, N. and Hitch, G.J. (1999) Memory for Serial Order: A Network Model of the Phonological Loop and Its Timing. Psychological Review, 106, 551. https://doi.org/10.1037/0033-295X.106.3.551

[17] Paulesu, E., Frith, C.D. and Frackowiak, R.S. (1993) The Neural Correlates of the Verbal Component of Working Memory. Nature, 362, 342-345. https://doi.org/10.1038/362342a0

[18] Blumstein, S.E. (1995) The Neurobiology of Language. 
[19] Embick, D., Marantz, A., Miyashita, Y., O’Neil, W. and Sakai, K.L. (2000) A Syntactic Specialization for Broca's Area. Proceedings of the National Academy of Sciences, 97, 6150-6154. https://doi.org/10.1073/pnas.100098897

[20] Henson, R.N.A., Burgess, N. and Frith, C.D. (2000) Recoding, Storage, Rehearsal and Grouping in Verbal Short-Term Memory: An fMRI Study. Neuropsychologia, 38, 426-440.

[21] Smith, E.E. and Jonides, J. (1997) Working Memory: A View from Neuroimaging. Cognitive Psychology, 33, 5-42.

[22] Smith, E.E., Jonides, J. and Koeppe, R.A. (1996) Dissociating Verbal and Spatial Working Memory Using PET. Cerebral Cortex, 6, 11-20. https://doi.org/10.1093/cercor/6.1.11

[23] Linden, M., Brédart, S. and Beerten, A. (1994) Age-Related Differences in Updating Working Memory. British Journal of Psychology, 85, 145-152. https://doi.org/10.1111/j.2044-8295.1994.tb02514.x

[24] Baddeley, A.D. (2004) The Psychology of Memory. The Essential Handbook of Memory Disorders for Clinicians, 1-13.

[25] Alvarez, G.A. and Cavanagh, P. (2004) The Capacity of Visual Short-Term Memory Is Set Both Byvisual Information Load and by Number of Objects. Psychological Science, 15, 106-111. https://doi.org/10.1111/j.0963-7214.2004.01502006.x

[26] Roozendaal, B. and McGaugh, J.L. (1996) Amygdaloid Nuclei Lesions Differentially Affect Glucocorticoid-Induced Memory Enhancement in an Inhibitory Avoidance Task. Neurobiology, Learning \& Memory, 65, 1-8. https://doi.org/10.1006/nlme.1996.0001

[27] Roozendaal, B. and McGaugh, J.L. (1997) Glucocorticoid Receptor Agonist and Antagonist Administration into the Basolateral But not Central Amygdala Modulates Memory Storage. Neurobiology, Learning \& Memory, 67, 176-179. https://doi.org/10.1006/nlme.1996.3765

[28] Killcross, S., Robbins, T. and Everitt, B.J. (1997) Different Types of Fear-Conditioned Behaviour Mediated by Separate Nuclei within Amygdala. Nature, 388, 377 380. https://doi.org/10.1038/41097

[29] Cahill, L. and McGaugh, J.L. (1998) Mechanisms of Emotional Arousal and Lasting Declarative Memory. Trends in Neurosciences, 21, 294-299.

[30] Loftus, E.F. (1993) The Reality of Repressed Memories. American Psychologist, 48, 518. https://doi.org/10.1037/0003-066X.48.5.518

[31] Colorado v. Connelly, 479 U.S. 157 (1986).

[32] Brown, J., Long-McGie, J., Oberoi, P., Wartnik, A., Wresh, J., Weinkauf, E. and Falconer, G. (2013) Confabulation: Connections between Brain Damage, Memory, and Testimony. Journal of Law Enforcement, 3, 1-11.

[33] Honts, C.R., Kassin, S.M. and Craig, R.A. (2014) "I'd Know a False Confession If I Saw One": A Constructive Replication with Juveniles. Psychology, Crime \& Law, 20, 695-704. https://doi.org/10.1080/1068316X.2013.854792

[34] Slovenko, R. (1999) Testifying with Confidence. Journal of the American Academy of Psychiatry and the Law, 27, 127-131.

[35] Loftus, E.F. and Pickrell, J.E. (1995) The Formation of False Memories. Psychiatric Annals, 25, 720-725. https://doi.org/10.3928/0048-5713-19951201-07

[36] Farrar, M.J. and Goodman, G.S. (1992) Developmental Changes in Event Memory. Child Development, 63, 173-187. https://doi.org/10.2307/1130911 
[37] Schneider, W. and Pressley, M. (2013) Memory Development between Two and Twenty. Psychology Press.

[38] Gathercole, S.E. (2009) Working Memory. In: Concise Learning and Memory: Editor's Selection, Elsevier Press, Amsterdam, 149-168.

[39] Gathercole, S.E., Pickering, S.J., Ambridge, B. and Wearing, H. (2004) The Structure of Working Memory from 4 to 15 Years of Age. Developmental Psychology, 40, 177. https://doi.org/10.1037/0012-1649.40.2.177

[40] Gathercole, S.E. (1999) Cognitive Approaches to the Development of Short-Term Memory. Trends in Cognitive Sciences, 3, 410-419.

[41] Davies, G.M. (1993) Children's Memory for Other People: An Integrative Review. In: Memory and Affect in Development. Minnesota Symposia on Child Psychology, Vol. 26, 123-157.

[42] Carey, S., Diamond, R. and Woods, B. (1980) Development of Face Recognition: A Maturational Component? Developmental Psychology, 16, 257.

[43] Flin, R.H. (1980) Age Effects in Children's Memory for Unfamiliar Faces. Developmental Psychology, 16, 373. https://doi.org/10.1037/0012-1649.16.4.373

[44] Kopelman, M.D. (2010) Varieties of Confabulation and Delusion. Cognitive Neuropsychiatry, 15, 14-37. https://doi.org/10.1080/13546800902732830

[45] Vrij, A. (2000) Detecting Lies and Deceit: The Psychology of Lying and Its Implications for Professional Practice. Wiley, Chichester.

[46] Vrij, A. (2005) Criteria-Based Content Analysis: A Qualitative Review of the First 37 Studies. Psychology, Public Policy, and Law, 11, 3.

https://doi.org/10.1037/1076-8971.11.1.3

[47] Lenroot, R.K. and Giedd, J.N. (2006) Brain Development in Children and Adolescents: Insights from Anatomical Magnetic Resonance Imaging. Neuroscience \& Biobehavioral Reviews, 30, 718-729.

[48] Clancy, S.A., Schacter, D.L., McNally, R.J. and Pitman, R.K. (2000) False Recognition in Women Reporting Recovered Memories of Sexual Abuse. Psychological Science, 11, 26-31. https://doi.org/10.1111/1467-9280.00210

[49] Porter, S., Birt, A.,Yuille, J. and Herve, H. (2001) Memory for Murder: A Psychological Perspective on Dissociative Amnesia in Legal Contexts. International Journal of Law and Psychiatry, 24, 23-42.

[50] Gaultney, J.F., Kipp, K. and Kirk, G. (2005) Utilization Deficiency and Working Memory Capacity in Adult Memory Performance: Not Just for Children Anymore. Cognitive Development, 20, 205-213.

[51] Kausler, D.H. (1991) Experimental Psychology, Cognition, and Human Aging. 2nd Edition, Springer Verlag, New York. https://doi.org/10.1007/978-1-4613-9695-6

[52] Salthouse, T.A. (1991) Theoretical Perspectives on Cognitive Aging. Lawrence Erlbaum, Hillsdale.

[53] Nyberg, L., Bäckman, L., Erngrund, K., Olofsson, U. and Nilsson, L.G. (1996) Age Differences in Episodic Memory, Semantic Memory, and Priming: Relationships to Demographic, Intellectual, and Biological Factors. The Journals of Gerontology Series B: Psychological Sciences and Social Sciences, 51, P234-P240. https://doi.org/10.1093/geronb/51B.4.P234

[54] Buckner, R.L. (2004) Memory and Executive Function in Aging and AD: Multiple Factors That Cause Decline and Reserve Factors that Compensate. Neuron, 44, 195208.

[55] Gudjonsson, G.H. (2003) The Psychology of Interrogations and Confessions: A 
Handbook. John Wiley \& Sons, New York.

[56] Gudjonsson, G.H., Sigurdsson, J.F., Sigfusdottir, I.D. and Young, S. (2012) False Confessions to Police and Their Relationship with Conduct Disorder, ADHD, and Life Adversity. Personality and Individual Differences, 52, 696-701.

[57] Vargha-Khadem, F., Gadian, D.G., Watkins, K.E., Connelly, A., Van Paesschen, W. and Mishkin, M. (1997) Differential Effects of Early Hippocampal Pathology on Episodic and Semantic Memory. Science, 277, 376-380.

https://doi.org/10.1126/science.277.5324.376

[58] Kessels, R., Kortrijk, H., Wester, A. and Nys, G. (2008) Confabulation Behavior and False Memories in Korsakoff's Syndrome: Role of Source Memory and Executive Functioning. Psychiatry and Clinical Neurosciences, 62, 220-225. https://doi.org/10.1111/j.1440-1819.2008.01758.x

[59] Van Oort, R. and Kessels, R. (2009) Executive Dysfunction in Korsakoffs Syndrome: Time Torevise the DSM Criteria for Alcohol-Induced Persisting Amnestic Disorder. International Journal of Psychiatry in Clinical Practice, 13, 78-81. https://doi.org/10.1080/13651500802308290

[60] Krabbendam, L., Visser, P.J., Derix, M.M., Verhey, F., Hofman, P., Verhoeven, W. and Jolles, J. (2000) Normal Cognitive Performance in Patients with Chronic Alcoholism in Contrast to Patients with Korsakoff s Syndrome. The Journal of Neuropsychiatry and Clinical Neurosciences, 12, 44-50. https://doi.org/10.1176/jnp.12.1.44

[61] Barba, G., Boissé, M., Bartolomeo, P. and Bachoud-Lévi, A. (1997) Confabulation Following Rupture of Posterior Communicating Artery. Cortex: A Journal Devoted to the Study of the Nervous System and Behavior, 33, 563-570.

[62] Singh, H.K. and Dhawan, B.N. (1992) Drugs Affecting Learning and Memory. Lectures in Neurobiology, 1, 189-207.

[63] Herrington, V. and Roberts, K. (2012) Addressing Psychological Vulnerability in the Police Suspect Interview. Policing, 6, 177-186.

https://doi.org/10.1093/police/par057

[64] O’Mahony, B.M., Milne, B. and Grant, T. (2012) To Challenge, or Not to Challenge? Best Practice When Interviewing Vulnerable Suspects. Policing, 6, 301-313. https://doi.org/10.1093/police/pas027

[65] Carmichael, et al. (1999) Kumho Tire Co., Ltd. v. 526 U.S. 137.

\section{Submit or recommend next manuscript to SCIRP and we will provide best service for you:}

Accepting pre-submission inquiries through Email, Facebook, LinkedIn, Twitter, etc. A wide selection of journals (inclusive of 9 subjects, more than 200 journals)

Providing 24-hour high-quality service

User-friendly online submission system

Fair and swift peer-review system

Efficient typesetting and proofreading procedure

Display of the result of downloads and visits, as well as the number of cited articles

Maximum dissemination of your research work

Submit your manuscript at: http://papersubmission.scirp.org/

Or contact jss@scirp.org 